from IgG to IgE. Low serum IgG and high IgE concentrations in smokers were found by Gerrard et al. ${ }^{11}$ That smoking may influence the immunological response is also indicated by the fact that it is mostly non-smokers who develop IgG antibodies and extrinsic allergic alveolitis on exposure to airborne antigens. ${ }^{1516}$ The increased atopic sensitisation in persons with inherited mucosal defects ${ }^{4-6}$ supports this theory, which fits the concept of a mucosal factor in the pathogenesis of atopy. ${ }^{3}$ The report of an association between viral infections, increase in serum IgE concentration, and sensitisation in children may also be explained by a transient mucosal defect. ${ }^{17}$

The prevalence of atopic diseases seems to have increased, especially in industrialised countries. Allergic rhinitis, for instance, was apparently rare at the beginning of the nineteenth century, while it is now common. Such a rapid increase cannot be explained by a change in man's genetic constitution; it is also unlikely that an augmentation in exposure to allergens, such as pollens and animal dander, has occurred. Exposure to substances that irritate the bronchi, however, has probably increased, and if IgE antibody production is enhanced by mucosal damage this offers an explanation for the increase of atopic airway disease. Blackley's comment in 1873 seems remarkably foresighted: "Perhaps this [increase] may in part be due to increased attention ... but it may also be accounted for by the greater prevalence of those conditions which act as predisposing and exciting causes." ${ }^{*}$ Air pollution and tobacco smoking may be such predisposing causes.

We are grateful for the secretarial help of Mrs Christina Gozzi, of the Uppsala county health authorities, and for the statistical advice from Mr Göran Nilsson, department of applied mathematics, Pharmacia AB, Uppsala. Allergen-coated filter-paper discs used in the radioallergosorbent test for IgE antibodies were kindly supplied by the research department of Pharmacia Diagnostics AB. We also thank Dr R Panzani (Marseilles) for the freeze-dried castor bean extract, and Draco AB, Lund, for the ispaghula powder. This work was supported in part by grants from the Swedish National Association against Heart and Chest Diseases, the Swedish Medical Research Council (Grant No 16 X -105), and Astma/allergiföreningen.

\section{References}

${ }^{1}$ Marsh DG, Bias WB, Ishizaka K. Genetic control of basal serum immunoglobulin $\mathrm{E}$ level and its effect on specific reaginic sensitivity. Proc Natl Acad Sci USA $1974 ; 71: 3588-92$.

${ }^{2}$ Zetterström O, Johansson SGO. IgE concentrations measured by PRIST in serum of healthy adults and in patients with respiratory allergy: a diagnostic approach. Allergy (in press).

${ }^{3}$ Leskowitz S, Salvaggio JE, Schwartz HJ. An hypothesis for the development of atopic allergy in man. Clin Allergy 1972;2:237-46.

4 Warren CPW, Tai E, Batten JC, Hutchcroft BJ, Pepys J. Cystic fibrosis -immunological reactions to a fumigatus and common allergens. Clin Allergy 1975;5:1-12.

${ }^{5}$ Warner JO, Norman AP, Soothill JF. Cystic fibrosis heterozygosity in the pathogenesis of allergy. Lancet 1976;i:990-1.

${ }^{6}$ Vanselow NA, Yamate M, Adams MS, Callies Q. The increased prevalence of allergic disease in anhidrotic congenital ectodermal dysplasia. fournal of Allergy 1970;45:302-9.

${ }^{7}$ Pepys J, Davies RJ. Occupational asthma. In: Middleton E, Reed CE, Ellis E, eds. Allergy principles and practice. Saint Louis: C V Mosby, 1978:812-42.

${ }^{8}$ Osterman K, Johansson SGO, Zetterström O. Allergy to coffee bean dust. Allergy 1978; 33:350.

${ }^{9}$ Machado L, Fagerberg E, Zetterström O. Occupational allergy in nurses to a bulk laxative. Allergy $1979 ; 34: 51-5$.

10 Bennich H, Johansson SGO. Immunoglobulin $\mathrm{E}$ and immediate hypersensitivity. Vox Sang 1970;19:1-3.

11 Gerrard JW, Heiner DC, Ko CG, Mink J, Meyers A, Dosman JA. Immunoglobulin levels in smokers and non-smokers. Ann Allergy $1980 ; 44: 261-2$

12 Nye L, Merret TG, Landin J, White RJ. A detailed investigation of circulating IgE levels in a normal population. Clin Allergy $1975 ; 5: 13-24$

${ }^{13}$ Kiviloog J, Irnell L, Eklund G. The prevalence of bronchial asthma and chronic bronchitis in smokers and non-smokers in a representative local Swedish population. Scand $\mathcal{F}$ Respir Dis 1974;55:262-76.

14 Tremonti LP. Tokyo-Yokohama asthma. Ann Allergy 1970;28:590-5.

${ }^{15}$ Morgan DC, Smyth JT, Lister RW, Pethybridge RJ. Chest symptoms and farmers' lung: a community survey. Br f Ind Med 1973;30:259-65.

16 Warren CPW. Extrinsic allergic alveolitis: a disease commoner in nonsmokers. Thorax 1977;32:567-9.

17 Frick OL, German DF, Mills J. Development of allergy in children. I. Association with virus infections. $\mathcal{F}$ Allergy Clin Immunol 1979;63: 228-41.

${ }^{18}$ Blackley CH. Experimental research on hay fever. (1873.) New ed. Pall Mall, London: Dawson, 1959:5.

(Accepted 27 fuly 1981)

\title{
Fracture of neck of the femur: changing incidence
}

\author{
A FENTON LEWIS
}

\begin{abstract}
From 1959 to 1977 the numbers of hospital admissions for fracture of the neck of the femur increased by a factor of 2.7. Detailed analysis of data from the Hospital In-Patient Enquiry for 1968-77 showed that the increase applied to both sexes and at all ages over 45 . The true incidence rate increased in parallel with the admission rate, and only a small part of the increased number of admissions was explained by the increasing numbers of the elderly.

The increasing incidence of fracture of the neck of the femur imposes great strain on hospital resources, particularly trauma and orthopaedic departments, and merits urgent investigation. An explanation for the increase might be that the experience of one demand-led condition characterises a greater need for health care among the elderly for other conditions.
\end{abstract}

Department of Health and Social Security, London SE1 6TE A FENTON LEWIS, MB, PHD, senior medical officer

\section{Introduction}

Our ability to estimate the incidence of fracture of the neck of the femur in the national population depends on careful interpretation of hospital activity data. The Hospital In-Patient Enquiry consists of a 10\% subset of hospital activity data and counts patients at the time of discharge or death, but the diagnosis is that pertaining at the time of admission. For simplicity these figures are described here as admissions.

\section{Hospital admissions}

Figure 1 shows the trend from 1959 to 1977 for England and Wales. Over the 18 years admissions for fracture of the neck of the femur increased nearly threefold, and except for a peak during the adverse winter of 1963 the trend was stable from year to year. Two other conditions are shown for comparison-namely, fracture of the skull and face and fracture of some other part of the femur. These showed a paitern over time closely similar to admissions for all conditions.

The 10-year period 1968-77 was examined in more detail. This avoided the early phase of development of the Hospital In-Patient Enquiry and gave a period where constant quality of data and reasonable consistency of clinical practice in treating the condition might be 
expected. Reference tables from the inpatient inquiry give admissions for the diagnosis in 10-year age bands up to 85, and fig 2 shows the trend over the decade studied for men and women aged 45 and over. The estimated number of admissions for men of all age groups increased by $55 \%$ over the 10 years and for women this increase was $65 \%$. The age-specific admission rate increases by a factor of about 3 for every decade, and this age effect was maintained over the period, as was the relation between the sexes (around 2 to 1 in the older age groups).

\section{Do admissions reflect true incidence?}

True morbidity data that will permit a valid comparison over time are almost impossible to obtain. Most of what we know about disease is gained during treatment and tells us not about the population

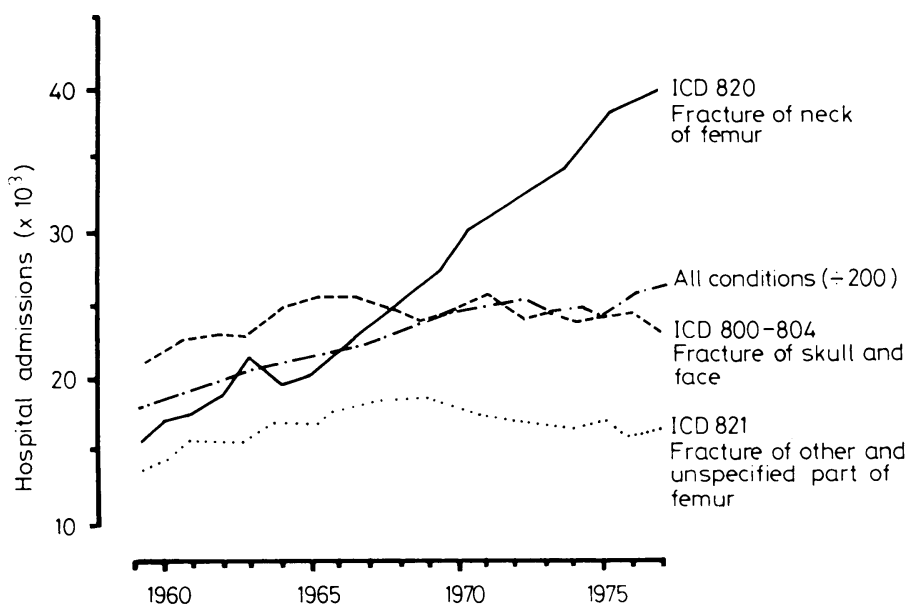

FIG 1-Estimated hospital inpatient admissions (England and Wales) for fracture of neck of femur and other conditions. Admissions for "All conditions" reduced to comparable scale by dividing by 200 (Hospital In-Patient Enquiry).

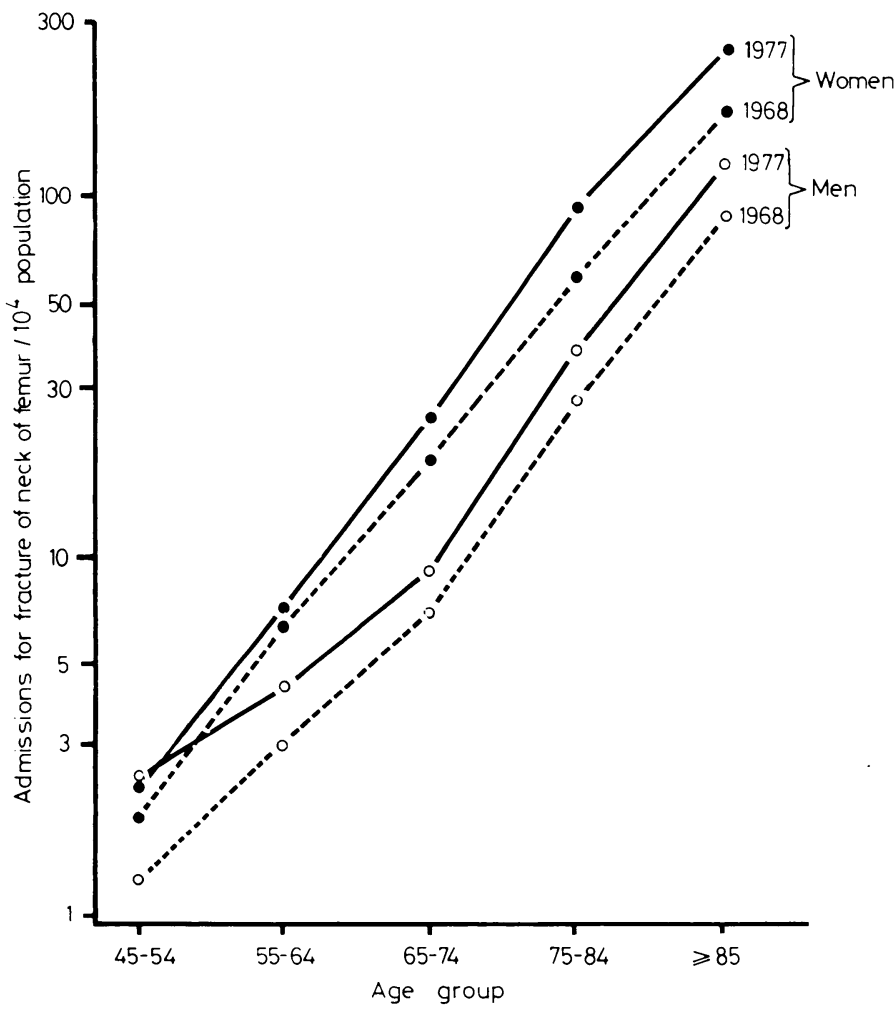

FIG 2-Hospital inpatient admission rates (England and Wales) for men and women in 1968 and 1977 where diagnosis on admission was fracture of neck of femur (Hospital In-Patient Enquiry). Standard errors approximately $10 \%$ of rates shown. but about those who seek and manage to obtain health care. The crucial question is therefore whether the increase in admission rates truly represents an increase in age-specific incidence. Fracture of the neck of the femur requires admission to hospital, usually as an emergency, though transfers are reasonably common when the initial admitting hospital cannot provide elective treatment. Thus some admissions will not represent a new fracture, and transfers between hospitals are usually counted as two separate admissions. Estimating the true incidence from admission data ${ }^{1}$ not surprisingly showed that the incidence was very close to the number of immediate admissions plus some of the transfers and some where coding has proved unsatisfactory. We are more concerned with the stability of this relation over time, but the proportion of admissions classified as immediate remained constant at around $75^{\circ}$ ", over the whole decade (around $16 \%$ being transfers in and the remainder waiting-list or booked cases).

Hip arthroplasty features increasingly in the elective treatment of fracture of the neck of the femur. Of the 8650 hip arthroplasties performed in trauma and orthopaedic departments in 1968, 36.1\% were for fracture of the neck of the femur, and these cases accounted for $12.5^{\circ}$ of all admissions for the fracture. By 1977, 27080 hip arthroplasties were being performed, of which $31.9 \%$ were for the fracture; and these accounted for $21.5 \%$ of all admissions for the condition. Probably this was the only major change in clinical practice over the decade, and the remaining data showed considerable evidence of consistency.

Hospital stay-The duration of stay for men remained constant at 34 days, and for women showed a small but non-uniform reduction from 43 to 39 days. In contrast, the overall duration of stay for all conditions fell by $12 \cdot 8^{\circ}$, from 15.6 days in 1968 to 13.6 days in 1977 .

Mortality in hospital among patients admitted for fracture of the neck of the femur remained constant over the decade at $16.1 \%$ for men and $16.8 \%$ for women; this was about 20 times the expected for a population of the same age. The Hospital In-Patient Enquiry records the number of deaths during the inpatient spell for which the diagnosis on admission was fracture of the neck of the femur. This does not mean that death was caused by the fracture, and such deaths greatly outnumbered registered deaths in which fracture of the neck of the femur was the stated cause. These hospital mortality figures are, however, more relevant, and a similar increased mortality has been observed in people falling at home, ${ }^{3}$ as has the increased risk of ischaemic heart disease in both sexes after fracture of the neck of the femur (J A Baldwin, J Fedrick, L E Gill, H Simmons, paper in preparation).

Admission and discharge rates-Regional admission rates for the fracture varied by a factor of 2 to 1 . Table I, however, shows an increase in admission rates over the period for all 14 English health regions together with Wales, though the size of the increase varied from $18^{\prime \prime}{ }^{\circ}$ in the Oxford region to $112^{\circ}{ }_{\circ}^{\prime}$ in the South-western. There was, however, a significant correlation between the discharge rates for the two years $(r=0.55 ; p<0.05)$ - that is, those regions with high admission rates in 1968 tended to be those with high rates in 1977. In general, pressure on hospital beds leads to shortening of the length of stay in an attempt to meet increased demand. Were this so for fracture of the neck of the femur there would be a negative correlation between the change in the discharge rate over the decade and the change in the mean duration of stay. In fact, the 15 regional figures showed a

TABLE I-Admission rates and durations of stay for fractures of femoral neck in 14 regions of England and in Wales in 1968 and 1977. Regions were regional hospital boards in 1968 but regional health authorities in 1977. Admission rates given by region of residence for both years

\begin{tabular}{|c|c|c|c|c|c|}
\hline \multicolumn{2}{|l|}{ Region } & \multicolumn{2}{|c|}{$\begin{array}{c}\text { Admission rates } / 10^{1} \\
\text { population }\end{array}$} & \multicolumn{2}{|c|}{$\underset{\text { (days) }}{\text { Mean duration of stay }}$} \\
\hline & & 1968 & 1977 & 1968 & 1977 \\
\hline Northern & . & $6 \cdot 6$ & $8 \cdot 0$ & $38 \cdot 9$ & $40 \cdot 1$ \\
\hline Yorkshire & . & 4.7 & $8 \cdot 3$ & $43 \cdot 8$ & $35 \cdot 8$ \\
\hline Trent . . . & . & $5 \cdot 1$ & $6 \cdot 9$ & $43 \cdot 0$ & $38 \cdot 1$ \\
\hline East Anglian ... & .. & $4 \cdot 4$ & $8 \cdot 6$ & $28 \cdot 5$ & $35 \cdot 2$ \\
\hline North-west Thames & $\therefore$ & 5.5 & $6 \cdot 6$ & $40 \cdot 7$ & $33 \cdot 2$ \\
\hline North-east Thames & . & $3 \cdot 7$ & $7 \cdot 8$ & $47 \cdot 7$ & 52.7 \\
\hline South-east Thames & . & $5 \cdot 3$ & $10 \cdot 5$ & $31 \cdot 3$ & 33.7 \\
\hline South-west Thames & . & $6 \cdot 4$ & 11.5 & $41 \cdot 1$ & $35 \cdot 7$ \\
\hline Wessex & . & $5 \cdot 1$ & $8 \cdot 1$ & $29 \cdot 4$ & $30 \cdot 5$ \\
\hline Oxford $\quad \ldots$ & .. & $5 \cdot 0$ & 5.9 & $50 \cdot 3$ & $23 \cdot 0$ \\
\hline South Western & . & $5 \cdot 2$ & $11 \cdot 0$ & $42 \cdot 9$ & $43 \cdot 7$ \\
\hline West Midlands & .. & 4.9 & $7 \cdot 3$ & $38 \cdot 0$ & $32 \cdot 3$ \\
\hline Mersey & . & $3 \cdot 4$ & $6 \cdot 3$ & $58 \cdot 5$ & $49 \cdot 5$ \\
\hline North Western & .. & $4 \cdot 4$ & $5 \cdot 9$ & $50 \cdot 4$ & $42 \cdot 2$ \\
\hline Wales .. & . & $6 \cdot 9$ & $10 \cdot 9$ & $34 \cdot 5$ & $34 \cdot 0$ \\
\hline England and Wales & & $5 \cdot 1$ & $8 \cdot 2$ & $41 \cdot 0$ & $37 \cdot 5$ \\
\hline
\end{tabular}


correlation between the change in admission rate and the change in duration of stay that was significantly positive $(r=0.57 ; \mathrm{p}<0.05)$; and this well illustrates the demand-led nature of the condition, the response in providing health care being highly elastic. This, of course, is essential if we are to conclude that true incidence is a constant proportion of hospital admissions, and it is important that there should be confirmatory evidence of this.

Surgical treatment-During 1972-7 the proportion of patients admitted who were treated by operation remained constant at around $70^{\prime \prime}{ }^{\prime}$. Hospital mortality was rather higher in those who were not operated on, and the relative risk of dying for them was $1.32\left(95^{\circ} \%\right.$ confidence limits $1 \cdot 22,1.43$ ).

Transfer to other units.-The geriatrician features increasingly in rehabilitation after fracture of the neck of the femur, and patients may be transferred to beds outside trauma and orthopaedic departments. These accounted for $19^{\prime \prime}$, of the beds used for the fracture in 1977 compared with $16^{\circ}{ }^{\circ}$ in 1968 . The specialty from which patients were discharged, however, showed no discernible trend, with just over $90^{\circ}$ " of all discharges being from trauma and orthopaedic beds. Although this trend is important, representing an increase of $76 \%$ in the use of other beds, it does not disturb the overall pattern of consistency.

\section{Effect of an aging population}

Fracture of the neck of the femur has long been known as characteristic of aging; Sir Astley Cooper noted over 150 years ago the thinning of bones that accompanied aging. There is now evidence that falls characterise illness and disablement with advancing age. ${ }^{4-6}$ Table II shows the change in the expectation of life for each sex over 25 years. The improvement is greater for women, and particularly for elderly women, so that this demographic change itself would lead to an increase in cases of fracture of the femur even without a change over time in age-specific incidence.

TABLE II-Expectation of life in years showing change over 25 years (home population of England and Wales)

\begin{tabular}{|c|c|c|c|c|c|c|}
\hline \multirow[b]{2}{*}{$\begin{array}{c}\text { Age } \\
\text { (years) }\end{array}$} & \multicolumn{3}{|c|}{ Males } & \multicolumn{3}{|c|}{ lemales } \\
\hline & $1948-50$ & $1973-5$ & $\begin{array}{c}\text { " } " 1 \\
\text { increase } \\
\text { over } 25 \\
\text { years }\end{array}$ & $1948-50$ & $1973-5$ & $\begin{array}{c}" \prime \\
\text { increase } \\
\text { over } 25 \\
\text { years }\end{array}$ \\
\hline $\begin{array}{r}0 \\
5 \\
15 \\
25 \\
35 \\
45 \\
55 \\
65 \\
75 \\
85\end{array}$ & $\begin{array}{r}66 \cdot 3 \\
64 \cdot 2 \\
54 \cdot 6 \\
45 \cdot 3 \\
36 \cdot 0 \\
27 \cdot 0 \\
18 \cdot 8 \\
12 \cdot 2 \\
7 \cdot 2 \\
4 \cdot 2\end{array}$ & $\begin{array}{r}69 \cdot 5 \\
66 \cdot 0 \\
56 \cdot 2 \\
46 \cdot 6 \\
37 \cdot 0 \\
27 \cdot 7 \\
19 \cdot 4 \\
12 \cdot 4 \\
7 \cdot 4 \\
4 \cdot 6\end{array}$ & $\begin{array}{l}4.8 \\
2.8 \\
2.9 \\
2.9 \\
2.8 \\
2.6 \\
3.2 \\
1.6 \\
2.8 \\
9.5\end{array}$ & $\begin{array}{r}71 \cdot 0 \\
68 \cdot 4 \\
58 \cdot 7 \\
49 \cdot 4 \\
40 \cdot 1 \\
30 \cdot 9 \\
22 \cdot 4 \\
14 \cdot 6 \\
8 \cdot 5 \\
4 \cdot 8\end{array}$ & $\begin{array}{r}75 \cdot 7 \\
72 \cdot 0 \\
62 \cdot 1 \\
52 \cdot 4 \\
42 \cdot 6 \\
33 \cdot 2 \\
24 \cdot 4 \\
16 \cdot 4 \\
9 \cdot 8 \\
5 \cdot 6\end{array}$ & $\begin{array}{r}6.6 \\
5.3 \\
5.8 \\
6.1 \\
6.2 \\
7.4 \\
8.9 \\
12.3 \\
15.3 \\
16.7\end{array}$ \\
\hline
\end{tabular}

An age-standardised admission ratio, comparable to the standardised mortality ratio, was calculated by applying the age-specific rates for 1968 to the population in each age band for 1977 to produce an expected number of admissions for that year. The observed value divided by this expected value gives the standardised ratio, which was 142 for men and 143 for women. The effect was therefore almost identical for men and women despite the large difference in admission rates between them (fig 2). The admission rate for men per 10000 population increased by $51.6 \%$ over the decade ( 3.94 against 2.60 ), and $81 \%$ of this increase was independent of the change in age structure of the population. For women the admission rate increased by $62.9 \%$ (12.80 against $7 \cdot 86)$, and $68^{\circ} \%$ of this change was independent of the change in age structure of the population.

\section{Discussion}

For the demand-led condition of fracture of the neck of the femur we have objective and reliable evidence that the incidence in older age groups and in both sexes increased materially (by $60 \cdot 6^{\circ}$ ) during $1968-77$. The age-adjusted component of this change was the greater part (almost $70^{\circ} \%$ ) and was identical in the two sexes, though the data were not robust enough to indicate whether this effect applied equally to all age groups.

We do not know whether this increase is attributable to a greater frequency of falls or to an increased risk of fracture when falling. Accelerated bone loss may have a hormonal or nutritional origin, ${ }^{6}$ and further examination of trends specific for age and sex may shed more light on this. There remains, however, the possibility that diminished activity in our society contributes to accelerated bone loss.

Reasons for an increased frequency of falls give rise to even greater speculation. Various retrospectively plausible suggestions may be put forward to explain what has happened. Alcohol consumption rises steadily, as does the use of drugs, particularly psychotropic drugs. The overall increase in alcohol consumption is known, and the General Household Survey $1978^{7}$ disclosed that $42^{\circ}{ }_{\circ}$ of men and $55^{\circ}{ }_{0}^{\circ}$ of women took medication during the 14 days before the interview, the proportions rising to $61 \%$ and $74 \%$ respectively in those aged 75 and over. In that age group $90^{\circ}$ " of the drugs were on prescription, and the remedy therefore rests with the prescribers.

If the similarity of the age-adjusted effect in the two sexes, as shown by these data, is genuine, this at least suggests that we should look for a factor that applies equally to men and women. There are very few demand-led conditions that affect both sexes and for which there is reasonable evidence that the provision of health care is adequate to meet that demand by hospital admission and subsequent open operation. Hospital admission is the only form of health care that is at present adequately documented nationally to provide reliable data, and even then we are restricted to conditions that are sufficiently common to provide adequate sample numbers for the Hospital In-Patient Enquiry. Were there other conditions meeting these criteria, then we could compare them and see to what extent there was a common factor suggesting increasing age-specific dependency on health care in the population. Without other such conditions there must remain some uncertainty about an intriguing and worrying explanation-namely, that our society is becoming less healthy and more dependent on health care, at any given age, than in the past.

Whatever the reason, the increase in need for hospital care to treat fracture of the neck of the femur has a major impact, particularly on departments of traumatic and orthopaedic surgery. The proportion of occupied beds in these departments devoted to the care of the fracture rose from $13.3 \%$ to $18.3 \%$ over the decade, while at the same time a higher proportion of the total care was being provided in other departments, making an overall increase in bed use of $48 \%$. The additional 16000 admissions a year used about 600000 bed-days at a cost of $£ 40$ million yearly. Returning to the number of admissions of 1968 for fracture of the neck of the femur would free 1650 mainly orthopaedic beds for patients on wait: $n$ g lists-that is, about $9 \%$ of the total capacity of trauma and orthopaedic departments.

The change in dependence on health care for the fracture may be interpreted as a change in effective age for health-care purposes (the horizontal interval between the 1977 and 1968 lines in fig 2), which was of the order of two to four years over the decade. Is this just a change of a highly specific nature affecting just one condition or is it indicative of greater overall dependence in the population?

I am indebted to members of the statistics division of the DHSS for providing data for this study and colleagues in both the NHS and DHSS for ideas and advice. The views stated in this paper are my own and not necessarily those of the DHSS.

\section{References}

${ }^{1}$ Williams BT. Femoral neck fractures. Br Med $\mathcal{F}$ 1977;i :171-2.

2 Grimley Evans J. Fractured proximal femur in Newcastle upon Tyne. Age Ageing 1979;8:16-24.

3 Wild D, Nayak USL, Isaacs B. How dangerous are falls in old people at home? Br Med f 1981 ;282:266-8. 
4 Grimley Evans J, Prudham D, Wandless I. A prospective study of fractured proximal femur: incidence and outcome. Public Health 1979;93: 235-41.

5 Brocklehurst JC, Exton-Smith AN, Lempert Barber SN, Hunt LP, Palmer MK. Fracture of the femur in old age: a two-centre study of associated clinical factors and the cause of the fall. Age Ageing 1978;7: 7-15.
6 Baker MR. An investigation into secular trends in the incidence of femoral neck fracture using Hospital Activity Analysis. Public Health 1980;94: 368-74.

${ }^{7}$ Office of Population Censuses and Surveys. General household survey 1978. London: HMSO, 1980.

(Accepted 5 August 1981)

\section{SHORT REPORTS}

\section{Aspiration around high-volume, low-pressure endotracheal cuff}

Evidence suggests that low-pressure, high-volume endotracheal tube cuffs may permit leakage of material past them. ${ }^{12}$ Studies performed on dogs' tracheas and on glass tubes used as models of the human trachea showed that liquid passed around folds in the cuff. ${ }^{3}$ We report a case in which material tracked around the folds in a high-volume, low-pressure cuff that was properly inflated.

\section{Case report}

A 65-year-old man had undergone resection of the middle third of his oesophagus because of carcinoma; his condition deteriorated after the operation and he was admitted to the intensive therapy unit, where he was intubated with a $9 \mathrm{~mm}$ Mallinckrodt $\mathrm{Hi}$-Lo oral endotracheal tube and intermittent positive-pressure ventilation was started using a Cape ventilator. The next day he was placed in the sitting position and barium was inserted into his upper oesophagus to test oesophageal anastomosis. A chest $x$-ray film showed that barium had spilled over into the oropharynx and tracked around the folds of the inflated cuff into the trachea and left main bronchus (figure).

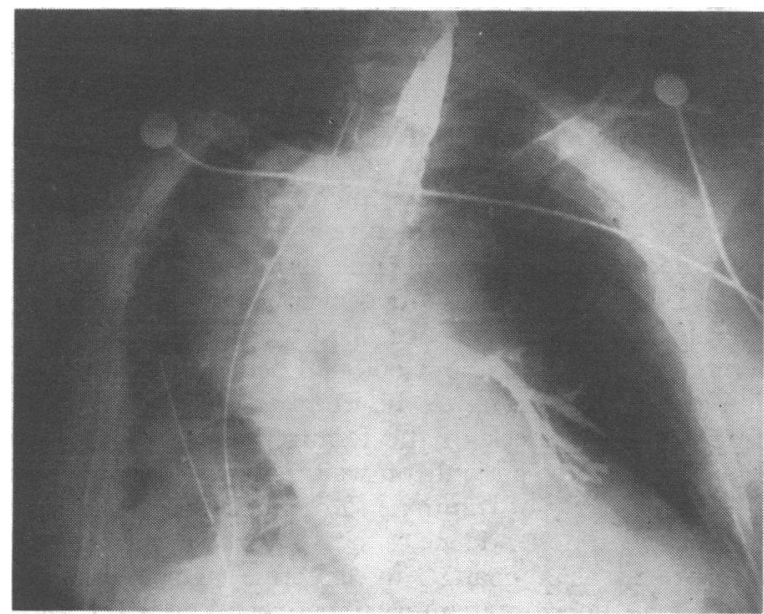

Aspiration around a low-pressure, high-volume cuff.

The cuff pressure had been checked routinely and was $18 \mathrm{~cm}$ water, which is within the recommended range; there was no audible leak during the inspiratory phase of ventilation. The peak inspiratory pressure was $24 \mathrm{~cm}$ water and the expiratory pressure atmospheric. The patient himself was making no inspiratory effort.

\section{Comment}

The advantages of high-volume, low-pressure cuffs over lowvolume, high-pressure cuffs are well established. ${ }^{45}$ In the intensive therapy unit at this hospital low-pressure, high-volume cuffs are used exclusively. Patients are clearly at risk, however, if material is allowed to collect in the oropharynx. Frequent sucking out to maintain a clear oropharynx is essential. Our case serves as evidence that material may track around the folds of a cuff which is being maintained at a pressure that is assumed to be safe. We would agree with Bernhard et $a l^{2}$ that a compromise may be needed, so instead of using the lowest inflation pressure at which no leak can be detected audibly a pressure of $25 \mathrm{~cm}$ water should be used routinely. This pressure will confer the benefits of low-pressure, high-volume cuffs but the possibility of aspiration will be reduced.

${ }^{1}$ Routh G, Hanning CD, Ledingham IM. Pressure on the tracheal mucosa from cuffed tubes. Br Med $\mathcal{F} 1979 ; \mathrm{i}: 1425$.

2 Bernhard WN, Cottrell JE, Sivakumaran C, Patel K, Yost L, Turndof H. Adjustment of intracuff pressure to prevent aspiration. Anesthesiology $1979 ; 50: 363-6$.

3 Pavlin EG, Van Nimwegan D, Hornbein TF. Failure of a high compliance low pressure cuff to prevent aspiration. Anesthesiology 1975;42:216-9.

4 Leigh JM, Maynard JP. Pressure on the tracheal muscoa from cuffed tubes. $\mathrm{Br}$ Med $\mathcal{F} 1979 ; \mathrm{i}: 1173-4$.

5 Dobrin P, Canfield T. Cuffed endotracheal tubes, mucosal pressures and tracheal wall blood flow. Am $\mathcal{F}$ Surg 1977;133:563-8.

(Accepted 27 fuly 1981)

Division of Anaesthesia and Intensive Therapy Unit, Western Infirmary, Glasgow

WILLIAM MACRAE, MB, FFARCS, senior registrar

PETER WALLACE, MB, FFARCS, consultant

\section{Laburnum "poisoning"}

Occasionally there are alarming accounts in the press or on the radio or television to the effect that a small child has eaten laburnum seeds and been rushed as an emergency to hospital, presumably in dire danger. The outcome is seldom heard. Understandably, the laburnum has come to be regarded toxicologically as an ogre, and representations are often made to have such trees felled and destroyed wherever children are likely to come into contact with them.

What is the authority for this view ? According to British poisonous plants ${ }^{1}$ an invaluable bulletin issued by the Ministry of Agriculture, Fisheries, and Food, "After the yew tree, the laburnum is the most poisonous tree grown in Britain; all parts of it are toxic, the wood, bark and roots being consistently so throughout the year..." The bulletin goes on to declare that, "Numerous cases are recorded of laburnum poisoning of human beings who have eaten the flowers or seeds, or who have carried twigs or bunches of flowers in their mouths. The features are dilatation of the pupils, stomach pains, vomiting, giddiness, weakness, coldness of the limbs, incoordination, and death from asphyxia." Lampe and Fagerstrom ${ }^{2}$ give an even more horrifying clinical description. Thus it was only to be expected that the National Poisons Information Service should annotate its index accordingly and prepare for the worst whenever a call was received about this plant. We investigated the outcome of suspected laburnum poisoning in children in 1979.

\section{Patients, methods, and results}

During 1979 all inquiries received from doctors about suspected laburnum poisoning were carefully recorded and followed up. Among 49 cases, comprising 20 children under 5 years and 29 aged from 5 to 12 , no symptoms were found in 34 . Among the remainder the symptoms were nausea and vomiting (12 cases), abdominal pain (seven), sore mouth (three), drowsiness (two), delirium (two), and diarrhoea (one). The duration of symptoms was 